\title{
La casa propia, territorio de libertad.
}

\section{The own house, a place of freedom.}

Recibido: Enero 2018

Aceptado: Agosto 2018

\section{Resumen}

La casa que el arquitecto construye para sí mismo constituye un acto libre, de vida y de arquitectura. Los arquitectos de la modernidad han construido casas propias en todas las geografías y con todos los formatos. Es ésta una de las tipologías de vivienda en la que la experimentación es mayor, muestra de las diferentes posiciones frente a un mismo acto, el del hombre que construye su propia casa. Observar estas obras desde la inversión entre lo vital y lo racional, que nos propone el filósofo Ortega y Gasset en El tema de nuestro tiempo (1923) nos permite descubrirlas en su mayor plenitud y establecer relaciones dispares entre ellas. En estas viviendas la relación entre la vida y la arquitectura es intensa, y la casa, como obra artística, se somete al devenir y al habitar. Pero también el hombre, a través de su vivir en ellas, renueva su confianza en la arquitectura. Una lectura de estas obras a través de los distintos modos de habitar y de construir nos permitirá descubrir aspectos de ellas, invisibles ante una lectura más disciplinar.

\section{Palabras Clave:}

Casa del arquitecto; Proyecto arquitectónico; Cultura del habitar, poética de lo cotidiano.
Anna Martínez Duran ${ }^{1}$

\section{Abstract}

The house that the architect builds for its own, constitutes a free act, of life and architecture. The modern architects have built their own houses in all geographies and with all formats. This is one of the housing typologies in which experimentation is greater, as it shows the different positions facing the same act, the man who builds his own house. To observe this works from the inverse relation between the vital and the rational, as the philosopher Ortega y Gasset proposes in El tema de nuestro tiempo (1923), allows us to discover them fully and establish different relations among them. In these dwellings, the relationship between life and architecture is intense, and the house, as an artistic work, submits to becoming and inhabiting. But also, the man, through his living in them, renews his confidence in architecture. A reading of these works through the different ways of living and building will allow us to discover aspects of them, invisible to a more disciplined reading.

\section{Keywords:}

The architect's house; Architectonic design; Culture of inhabiting; Poetics of the everyday life.

\footnotetext{
${ }^{1}$ Adscripción: Escuela de Arquitectura La Salle, Universidad Ramón Llull; España. Doctora en Arquitectura. amartinez@salleurl.edu
} 


\section{La construcción de la casa, un hecho vital y arquitectónico.}

El arquitecto que construye su casa lo hace como un acto de libertad individual. A la vez un acto de vida, un acto de arquitectura.

La casa es el lugar donde nos protegemos del mundo, también el sitio desde el cual observamos y nos proyectamos sobre el mundo. El lugar al cual escapar y el lugar desde el cual ordenar el mundo (Bachelard, 1965).

Son características de las casas propias el no tener cliente y el representar el ideal arquitectónico del autor. Aunque, al adentrarse algo más en la investigación, nos damos cuenta que "en casa del herrero, cuchillo de palo" y que nunca hay prisa por construir para sí mismo ${ }^{2}$.

Por el hecho de no tener cliente, estas viviendas son casi siempre ejemplos experimentales, innovadores y arriesgados, muchos de ellos rozando la legalidad. Siempre en relación con el resto de la obra propia, constituyen ejemplos paradigmáticos, extremos, de pura arquitectura. Se construye para uno mismo lo que no puede hacerse para los demás. Nuevas propuestas que no sólo afectan a la arquitectura, sino también al modo de habitarla, porque son la expresión de una forma de posicionarse en el mundo, de un ideal de vida.

Finalmente, es el hecho del habitar en la casa lo que pone a prueba la misma arquitectura. Ésta es sin duda, la característica más específica de la casa propia, su mayor capacidad. Con la vida en la casa, el arquitecto comprueba su propia arquitectura. También para los que nos aventuramos en su investigación, será la parte más difícil de conocer, porque una vez terminada, la casa se muestra al público, y se cierran las puertas. Ante todo, es el escenario de la vida íntima, y eso es algo que hay que proteger (Autora, 2011).

En este escrito se adopta genéricamente el término arquitecto como sujeto de la acción: del proyecto, la construcción y del habitar en la casa. Porque si bien es difícil conocer los entresijos de la vida de estos personajes, más lo será la de quienes comparten con ellos el riesgo de construir.
Valga pues un pequeño homenaje a las mujeres, esposas, compañeras, muy pocas constructoras, pero muchas dando apoyo a estas vidas complicadas, a estas obras compartidas.

\subsection{Como hecho cultural}

La arquitectura moderna va de la mano de la vivienda unifamiliar. Desde el proyecto de casa propia de Mies van der Rohe en Werder (1914) han pasado ya más de 100 años, en los cuales los arquitectos han seguido pensando y construyendo casas en las que vivir. En las distintas geografías y con todo tipo de formatos, la casa propia se presenta como ejemplo de diversidad tipológica y de experimentación arquitectónica.

Riqueza en las soluciones arquitectónicas, pero también en las diferentes maneras de habitar. Porque el arquitecto, cuando construye su propia casa, ejerce de hombre libre, plural en las diferentes culturas, y propone "estas nuevas estructuras, novísimas, en sus obras y en sus vidas" (De la Sota, 1989, 225) ${ }^{3}$.

El hombre es por naturaleza manipulador, hacedor de cosas. La construcción de la casa familiar es en muchas culturas una actividad comunitaria, y constituye un acto de afirmación colectivo. En nuestro mundo civilizado, sólo los pájaros, los conejos, los grillos, las hormigas... y los arquitectos, son libres de ejercer el derecho a construir su propio hogar.

Escritores, músicos, filósofos, poetas, han dispuesto históricamente su cabaña en el jardín. Lugar modesto, reducido, cerrado, alejado del ruido y el quehacer cotidiano de la casa. Inmersas en la naturaleza, las cabañas han sido siempre el lugar donde pensar, donde concentrarse. La más conocida la de Heidegger en Todtnauberg (Sharr, 2008), pero también Virginia Wolf, Gustav Mahler, August Strindberg, o el arquitecto Carlos Raúl Villanueva, disponían de estos lugares de trabajo, refugios en los que aislarse (Outeiro, 2011). "Cobijo, refugio, trinchera, guarida, tabernáculo, estancia provisional de costumbres o inciertos porvenires...", estos espacios domésticos son los lugares "donde la vida se expresa a través del artificio" (Cid, Sala, 2012).

\footnotetext{
${ }^{2}$ Se parte del presupuesto de que el arquitecto es el propio cliente. Pero sí que tiene familia, un presupuesto a veces ajustado, un trabajo y una vida no siempre fáciles. Es por ello que se relativiza el término de casa ideal. Es a pesar de ser para sí mismo, y de la libertad de acción que ello comporta, una arquitectura real, vinculada a la vida.

3 Alejandro de la Sota en "La grande y honrosa orfandad".
} 
En las casas propias es el mismo arquitecto quien da forma a su cobijo, y nos muestra con ello su manera de entender la vida y la arquitectura, el cómo vivir y el cómo construir. Estas viviendas ejemplifican, más que ningún otro tipo edificatorio, la relación entre el hombre y el arquitecto, entre el autor y su obra: su vida, sus valores, sus modos de hacer y de pensar. Y como se comprobará, se trata de una relación profunda, intensa, y repetida (Autora, 2008).

\subsection{Vida y arquitectura}

La vida que se instaura con la modernidad tiene sus propias connotaciones, que la diferencian de la existencia en el pasado. Nuevos valores en la vida que coinciden con los del nuevo arte, el que nace con las vanguardias. En consecuencia, también las relaciones entre ambos, arte y vida, son distintas en esta nueva época. Nos encontramos frente a un arte diferente, pero también la actitud y los modos de actuar del artista han cambiado, y con ello sus intereses y preferencias. La necesidad de verdad de ambas actuaciones es preconizada por el mismo Mies en la frase: "La verdadera forma presupone una vida verdadera" (Neumeyer, 1995, 393) ${ }^{4}$, una afirmación que pone en relación los dos polos de gravitación de esta nueva época, el arte y la vida.

En la estimación de esta nueva relación es el filósofo Ortega y Gasset quien establece las bases con mayor claridad: "El tema de nuestro tiempo consiste en someter la razón a la vitalidad, localizarla dentro de lo biológico, supeditarla a lo espontáneo. Dentro de pocos años parecerá absurdo que se haya exigido a la vida ponerse al servicio de la cultura. La misión del tiempo nuevo es precisamente convertir la relación y mostrar que es la cultura, la razón, el arte, la ética quienes han de servir a la vida." (Ortega y Gasset, 1981, 117).

Someter el arte a la vida será la primera consecuencia de su nueva propuesta, pero también sustituir la razón pura por la razón vital: "la cultura del intelecto abstracto no es, frente a la espontánea, otra vida que se baste a sí misma y pueda desalojar a aquélla. Es tan sólo una breve isla flotando sobre el mar de la vitalidad primaria.
Lejos de poder sustituir a ésta, tiene que apoyarse en ella, nutrirse de ella, como cada uno de los miembros vive del organismo entero" (Ortega y Gasset, 1981, 116). Con ello se pone fin a una época que según él arranca con el descubrimiento de la razón por Sócrates. La racionalidad se presenta como una parte de la vida y por tanto no con capacidad para dar explicaciones cerradas del mundo.

\subsection{El valor de lo cotidiano}

Consecuencia de esta apreciación desinteresada de la vida, el artista ejerce su trabajo, no como un "gesto triste que pretende justificarse con patéticas consideraciones sobre los deberes humanos y la sagrada labor de la cultura" (Ortega y Gasset, 1981, 141), sino más bien como un juego, un deporte, una actividad hecha con humor, generosa y no impuesta. Al restar trascendencia al resultado final, se enriquece el camino y el artista "hará sus creaciones como en broma y sin darles gran importancia. El poeta tratará su propio arte con la punta del pie, como buen futbolista" (Ortega y Gasset, 1981, 142). Ésta es una de las conclusiones más interesantes de la propuesta vital de Ortega, y consiste en apreciar que es el esfuerzo espontáneo, generoso y deportivo el que dignifica la actividad, más que el resultado en sí mismo. Esta afirmación tiene una relación directa con el arte moderno, en el que se valora más el proceso seguido que el resultado en sí mismo, que además nunca es único, y depende directamente de él.

Consecuencia de ello y de este "se hace camino al andar", adquiere mayor protagonismo lo cotidiano y diario. No sólo la actividad, sino los espacios y los objetos que nos rodean. El artista fija la atención en las cosas cercanas, en la naturaleza mínima y diaria. Aparecen poesías y canciones en las que son las moscas, los gorriones, las lunas, los amaneceres, las espigas y las mariposas los protagonistas de los nuevos cantares. En pintura son los platos, las botellas, los libros o las guitarras, los que entran en juego. En arquitectura los espacios y los objetos domésticos, los del habitar.

\footnotetext{
${ }_{5}^{4}$ Mies van der Rohe en Sobre la forma en arquitectura.

${ }^{5}$ Convertida en dicho popular, del poeta Antonio Machado en los Proverbios y cantares XXIX, Campos de Castilla.
} 


\section{Modos de habitar, modos de construir.}

En las casas que los arquitectos construyen para ellos mismos se hace patente de una forma intensa esta nueva relación entre la vida y el arte. Son casas construidas en el nuevo entorno que la modernidad propone y ejemplifican con claridad este sometimiento del arte a la vida.

Ser conscientes de este nuevo entorno de lo vital que Ortega propone, y que las vanguardias confirman, permite observar estas obras desde un nuevo punto de vista, otra forma de mirar que sacará a la luz aspectos diferentes, que quedaban ocultos frente a una lectura más racional.

Se establecen para ello cuatro categorías, que tienen en cuenta los modos de construir y de habitar en relación con la naturaleza, con el paso del tiempo, con la tradición, y con el hombre en sí mismo.

\subsection{El pacto con la naturaleza}

La relación con la naturaleza constituye una premisa básica de proyecto y como no, en su casa, el arquitecto busca el participar de ella. Refugios como los de Knut Knutsen en Portör, Noruega (1949), Marco Zanusso (1964) en la costa de Arzachena, Ramón Vázquez Molezún en A Roiba (1969), o Ryue Nishizawa (1998) en un claro del bosque, constituyen ejemplos bien distintos de implantación en el entorno natural.

Figura 1. Casa Knutsen, Portör (Noruega)

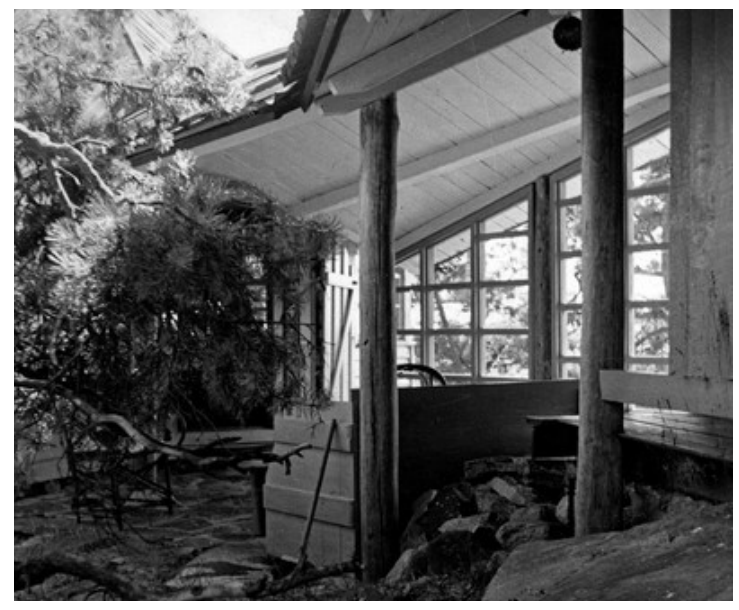

Fuente: Nasjonal Museet.
Los elementos del paisaje, habitantes del lugar antes de la llegada del arquitecto, se introducen en el proyecto (Neutra, 1951): la roca a la que se pega la casa de Stënnas (1937), el algarrobo de Le Cabanon (1952) o el lago, frente al que se dispone la casa VDL de Richard Neutra (1932), cuya cubierta de madera versiona la "Plataforma para contemplar la Luna" del Palacio Katsura

\section{Figura 2. La Cabanon, Cap Martin (Francia)}

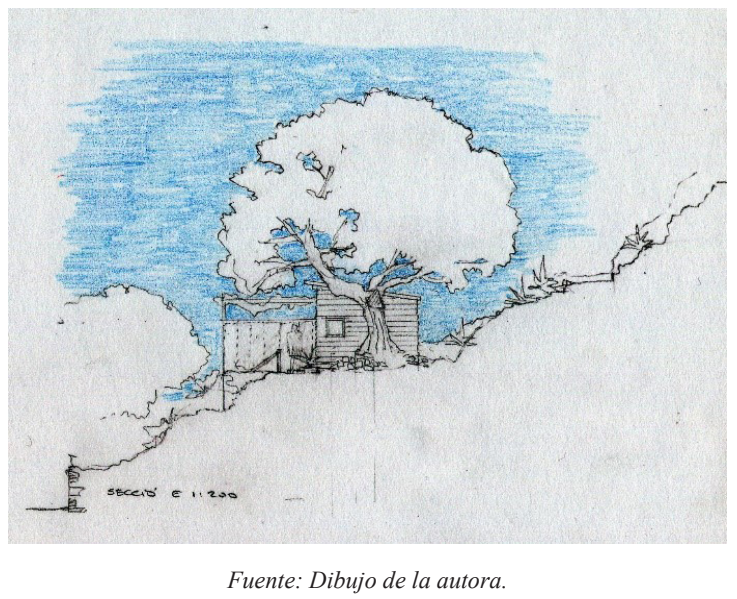

Introducir el sol en casa o protegerse de los vientos y la tempestad, son principios básicos para cualquiera que quiera instalarse en un lugar en equilibrio con la naturaleza: “... un banco fijo en la casa de Hellebaek. El sol ahí daba de lleno, y Lis y yo pasamos horas sentados en este banco, calentándonos" (Moller, 2004) ${ }^{6}$. Con acciones cotidianas como prender la chimenea, recoger el agua de lluvia, cocinar al aire libre, el habitante participa de los cambios, de los días y las estaciones: "La ventana abierta, el rayo de sol furtivo, rayos y truenos, la llama chisporreante, la cama debajo las estrellas, son experiencias emocionantes que no deben ser eliminadas de nuestra vida diaria" (Schindler, 1984, 40). En la casa de Erik Gunnar Asplund (1937) la excursión nocturna a la caseta del inodoro, "al abrigo de un bosquecillo de donde nos llega un olor a verdor y a musgo" (Tanizaki, 1994, 15), se convierte para los hijos del arquitecto en una experiencia de vida. A veces esta cercanía llega a convertirse en una comunión, casi religiosa, con la madre naturaleza, como en el caso de Luigi Figini en Milán (1934). Éste recoge, en un libro que pensaba titular "La

\footnotetext{
${ }^{6}$ Mies van der Rohe en Sobre la forma en arquitectura.
} 
vida social de los pájaros", imágenes de los gorriones, mirlos y petirrojos que acuden a las terrazas a picotear en las zarzas, a beber agua en el estanque, a sorber un trozo de sandía que alguien ha olvidado.

Figura 3. Casa Figini, Milán (Italia)

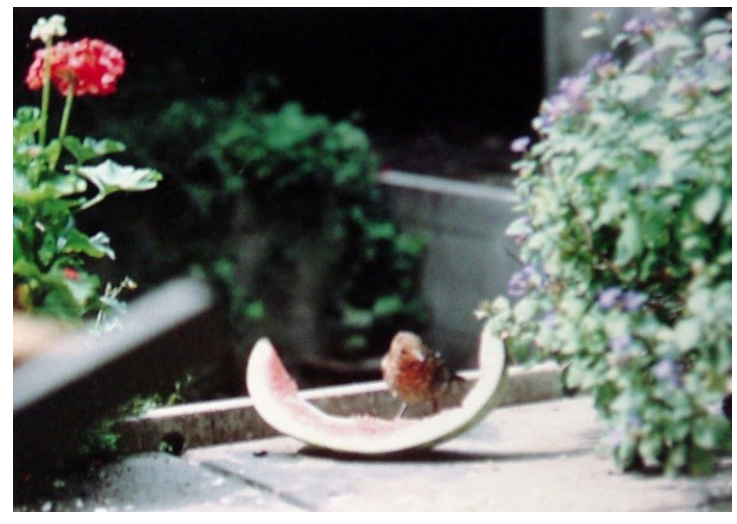

Fuente: Archivo Figini AAF.

En estas obras, la vida se somete al orden de la naturaleza, en un intento del arquitecto "por reinstaurar "las condiciones de la naturaleza" en la vida de los hombres" (Petit, 1970, 279)7.

En la búsqueda de esta convivencia con la naturaleza se evita la confianza ciega en la técnica, y se prefieren los sistemas tradicionales de adaptación al clima. En la casa de Rudolph M.Schindler (1921) se prescinde de los nuevos sistemas de iluminación difusa y calefacción radiante, habituales en aquellos momentos en California, y se confía en las ventanas-lucernario para la ventilación cruza$\mathrm{da}$, en las chimeneas para calentar y cocinar, y en un sistema de lámparas móviles, que escondidas en las dobles vigas, bajo ramas de eucalipto, proyectaban una luz coloreada y misteriosa.

Otras propuestas más arriesgadas en relación a climas extremos fuerzan la vida cotidiana en la casa, y se convierten en experiencias de proyecto: The Box en Lissma, Suecia, (1941), o Can Lis, en Porto Petro, Mallorca (1971). Los dos arquitectos, Ralph Erskine y Jörn Utzon, foráneos, recién llegados, adaptan mejor sus segundas versiones.

En todas ellas, más que la aspiración a tenerlo todo resuelto, se valora el esfuerzo, el ejercicio diario que enriquece la vida. Porque "las comodidades adormecen los sentidos", se aprecia, más que un confort artificial, la cercanía con la naturaleza.

\subsection{Casas que se mudan}

La construcción de la casa propia constituye un momento importante en la vida del arquitecto. Coincide con períodos de cambio y nuevos planteamientos vitales, y por ello también se presenta como un punto de inflexión en la obra. Caso cercano el de Villa Gloria (1959), que reforman Peter Harnden y Lanfranco Bombelli en su decisión de pasar temporadas en Cadaqués, donde se acabarán asentando personal y profesionalmente.

Figura 4. Villa Gloria, Cadaqués (España)

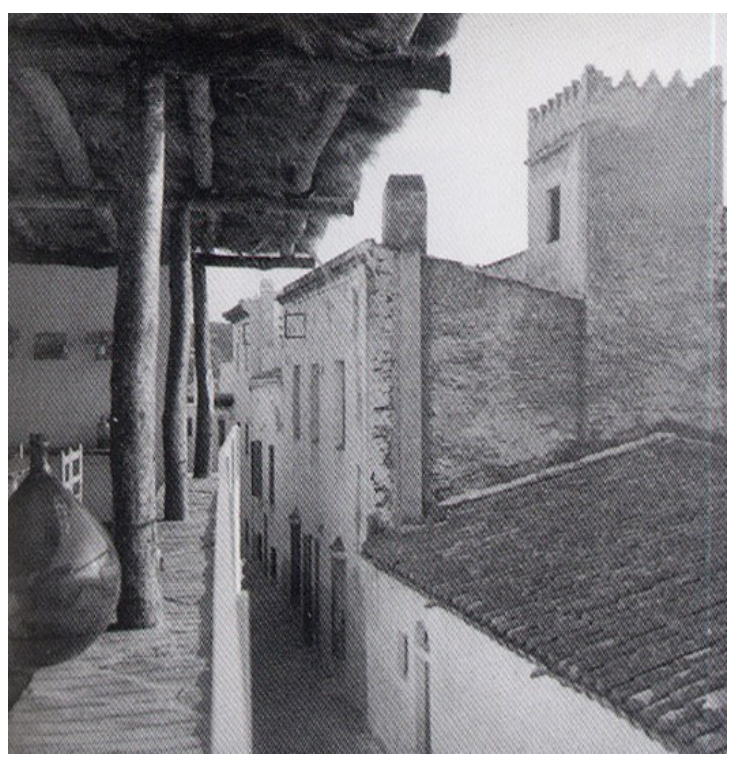

Fuente: Fons Harnden-Bombelli. Arxiu Fotogràfic COAC.

Las etapas de la vida: matrimonios, hijos, soledades... traen diferentes usuarios y distintas formas de habitar las casas. A veces, vida familiar $\mathrm{y}$ vida profesional se mezclan, como en Hvitträsk (1903), como nos muestra la bonita imagen de Pipsan Saarinen en el despacho de los tres arquitectos finlandeses. La presencia de los niños en la casa se resuelve con ingenio, desde las cortinas de la casa de Gerrit Th.Rietveld en Utrecht (1936), que transforman una sala única en varias habitaciones, hasta el ejemplo de Kyonori Kikutake (1958) que considera que la vida de los hijos en la casa es temporal, por lo que dispone unas células

\footnotetext{
${ }^{7}$ Le Corbusier (1957), traducción de la autora.

${ }^{8}$ Dicho atribuido popularmente a E.G.Asplund.
} 
prefabricadas que se cuelgan de la estructura de hormigón, y que en ningún momento modifican la vivienda original.

Figura 5. Casa Saarinen, Hvitträsk (Finlandia)

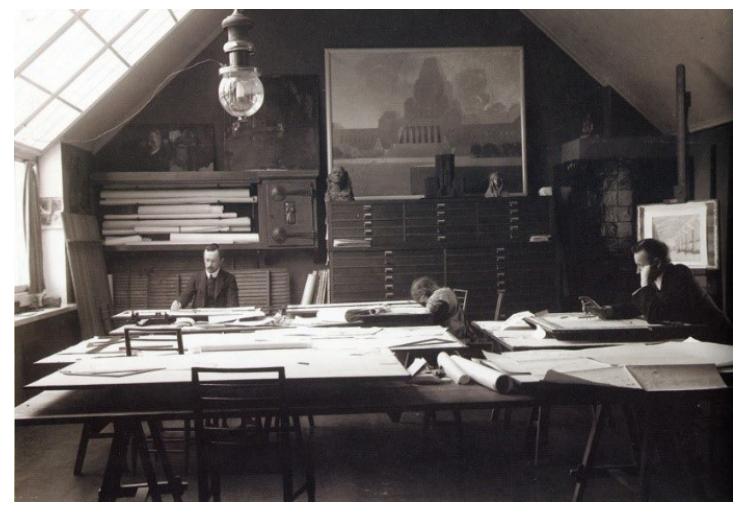

Fuente: Museum of Finnish Architecture.

Pero también está el que, con cada cambio, se muda y construye otra casa, distinta a la anterior. Son ejemplos de ello las cuatro de Marcel Breuer y Jörn Utzon (si incluimos Bailey) o las tres de Josep Lluis Sert y Frank Lloyd Wright ( $\sin$ contar Ocatillo, ni las reformas en Taliesin East), todos ellos nómadas modernos. Otros como Mies, plantean varias veces el proyecto de vivienda, pero ésta nunca llega a construirse, y el arquitecto, en su periplo en solitario, se muda de apartamento en apartamento. También Alvar Aalto, con Aino y Elissa, José Antonio Coderch, o Eileen Gray disponen de varias casas propias, en distintos momentos y lugares, que muestran los diferentes intereses de sus autores ${ }^{9}$. Finalmente, las viviendas de Alison y Peter Smithson, dentro de una misma filosofía del habitar, son muestra de las distintas tipologías: las de la ciudad (1952-1961-1971) y la de vacaciones en el campo, Upper Lawn (1962).

Siempre podemos distinguir la casa de juventud, que muestra la fuerza de tener toda una vida por delante, Schindler en Hollywood (1921), y la de la madurez, que acoge el retiro, el descanso del hombre que busca el abrigo del muro y la entrada suave de luz. Alejada de la ciudad, es un lugar de reposo, como lo serán Stënnas (1937), Muuratsalo (1953), Sa Penya (1960) o Frigiliana (1971).
Otras veces el arquitecto se enfrenta, ya de mayor, a la reforma de la casa familiar: Coderch en Espolla (1964), que él mismo recupera, tras haber sido vendida por un hereu sin hijos, la que él llama la "casa madre". Un caso parecido es el de Fernando Távora y la reforma de la mansión señorial de Covilha (1973): "Había que tocarla, y tocarla fue un acto de amor, largo y lento, persistente y cauteloso, con dudas y certezas" (Trigueiros, 1993, 128) ${ }^{10}$.

Figura 6. Casa Coderch, L'Espolla (España)

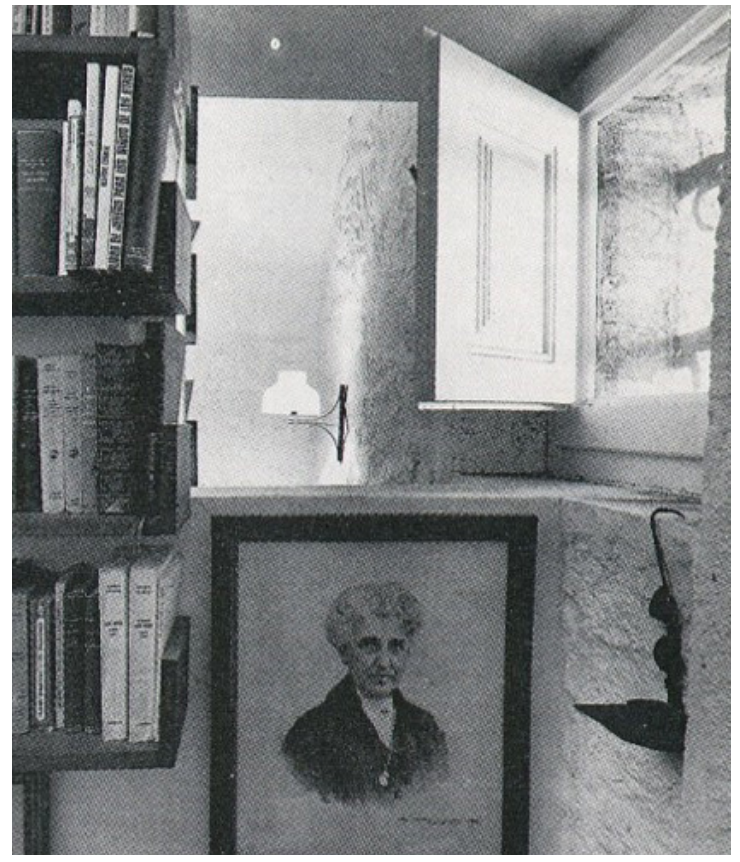

Fuente: Fons Català Roca. Arxiu Fotogràfic COAC.

Con los cambios que el paso de los años conlleva, las casas se transforman, en un proceso, no siempre fácil, por adaptar la arquitectura a la vida. La casa de Neutra sufre varias ampliaciones, diferentes, en las tres épocas en las que interviene, la última después del incendio (1932-1939-1965). También la casa de Julio Cano Lasso en La Florida (1955) es un ejemplo de modificación continua. Pero para ejemplo extremo, la vivienda de Mogens Lassen en Copenhague (1937-1963), que el autor transforma sin cesar a lo largo de su vida en ella. Porque "la arquitectura es como un ser vivo, se modifica conforme cambian las personas

\footnotetext{
9 Si Villa Flora (1926) o Plaza Calvó (1946) son primeras casas propias en las que el referente es la arquitectura popular, la casa E1027 (1926) es una apuesta de modernidad, que se hace más local en Lou Pérou (1954).

${ }^{10}$ Escrito de Fernando Távora, traducido por la autora.
} 
que la habitan. Una casa nunca está terminada, es un organismo en constante evolución" (Figueroa Castejón, 1989, 102). La vivienda del arquitecto dista mucho de ser un objeto intocable y perfectamente acabado. Al contrario, el habitante no duda en modificarla si es preciso.

La vida de la casa propia transcurre paralela a la del morador y a través del mutuo proponer y escuchar, la obra acaba cambiando y envejeciendo, a veces incluso llegando a contradecir intereses que parecían fundamentales en el proyecto inicial. Con el tiempo la jerarquía de valores del habitante se modifica, y la vivienda se adapta. Fruto de estos cambios, la obra acaba por contener elementos dispares que difícilmente podían haber nacido de un solo momento, de un único proyecto, y que finalmente la hacen mucho más digna y completa.

Para terminar, en algunos casos, la construcción de la casa constituye la mejor y más rica decisión de toda una vida. Una existencia, la del arquitecto y su familia, que acabará siendo deudora de la casa, en la que se refugia y protege. Vidas que se tornan prohibidas sobreviven con felicidad y equilibrio gracias a la luz, al espacio, al acierto de la casa propia. Es éste el caso especial y casi escalofriante de Konstantin Melnikov en su casa de Moscú (1927).

\subsection{Tradición y modernidad}

Estas obras instauran nuevas formas de vida y de arquitectura, que incorporan a los valores de la modernidad, elementos de la tradición. Algunas veces se rescatan costumbres arraigadas en el pasado, que el arquitecto ve cercanas a desaparecer, y otras se proponen innovadores modos de habitar y de construir, aunque con ello se arriesgue la vida propia y la de la familia, en una propuesta a veces difícil de llevar.

La estancia en la que se mezclan las diferentes funciones, propia de la arquitectura popular, se reivindica en estas casas en sus diferentes formas. En la sala de Stënnas, el matrimonio descansa, trabaja, recibe, se asea. También funciona como estancia única la casa de Erwin y Gisela Broner en Sa Penya, patio y dormitorio abiertos a la sala central.
Figura 7. Casa Asplund, Stënnas (Suecia)

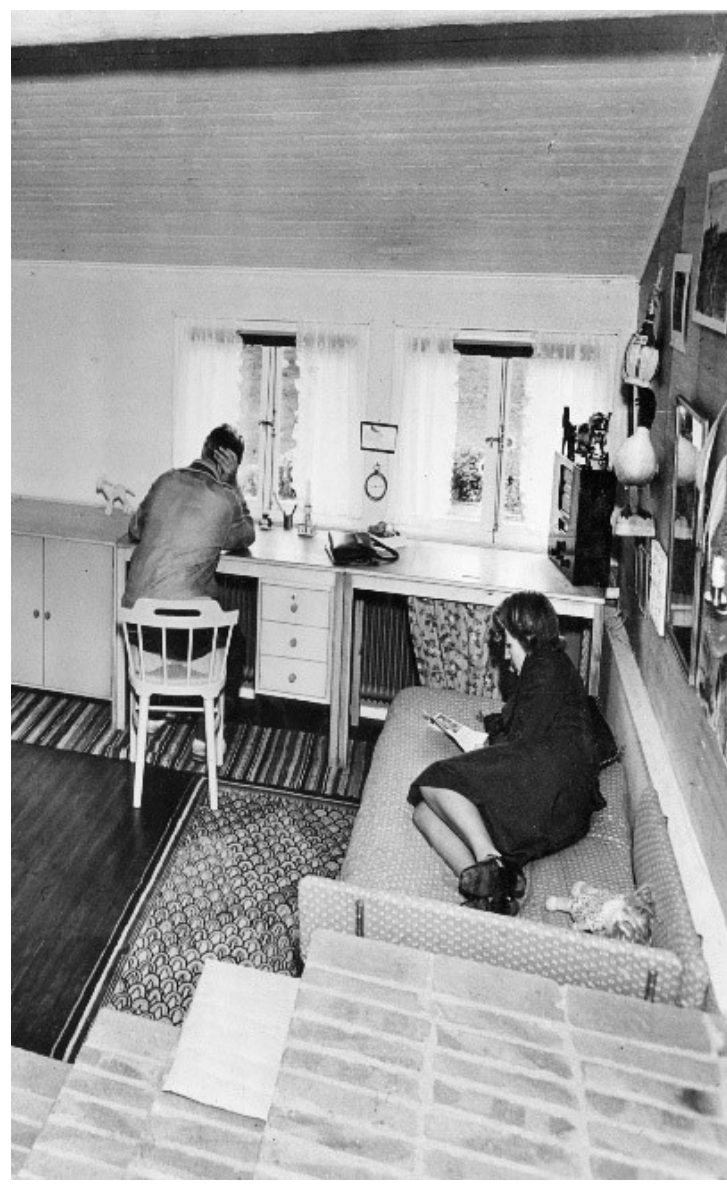

Fuente: Digitalt Museum.

Distribuciones inusuales para la época son las de la "Casa Cooperativa" de Schindler, en las que se asigna un espacio de vida, un estudio, a cada uno de los habitantes. Y también están las casas que se transforman del día a la noche, con muebles que se abren, se pliegan, se esconden: la de Arne y Grete Korsmo en Oslo (1955), o la cabaña en la que vivió y trabajó Erskine a su llegada a Suecia. Esta capacidad de soportar el trajín diario es la mejor garantía de una casa. En Frigiliana son los espacios exteriores los que acogen los planteamientos vitales del arquitecto. Una existencia ejemplar la del arquitecto vienés, que disfruta sus últimos años en una casa vacía, de apariencia popular: "lo que hace falta no es una nueva forma de construir, sino una nueva forma de vivir" (Fernández Galiano, 2007, 72) ${ }^{11}$.

\footnotetext{
11 Bernard Rudofsky en Sparta-Sybaris, citado en el articulo de Luis Fernández Galiano, "Esparta y Síbaris: Bernard Rudofsky, disciplina y hedonismo".
} 
Figura 8. Casa Rudofsky, Frigiliana (España)

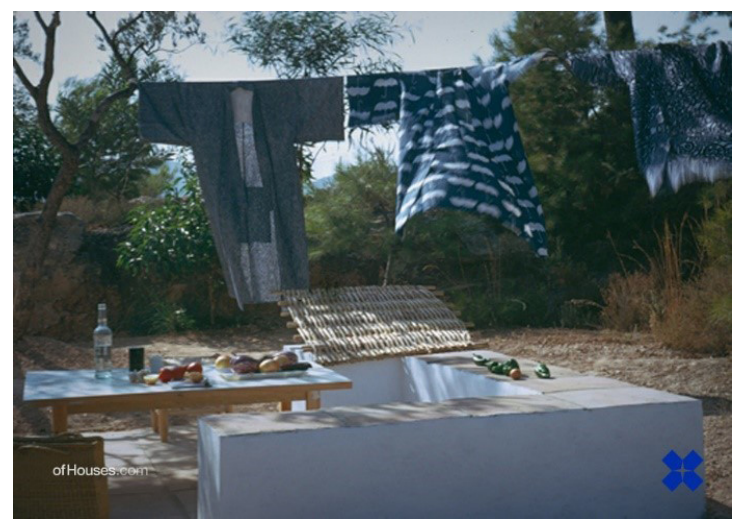

Fuente: The Bernard Rudofsky Estate Vienna.

En la vida moderna, como en el arte, se valora lo cotidiano: los quehaceres diarios y las cosas pequeñas. No son los grandes acontecimientos, los grandes placeres o las grandes ambiciones los que nos fijan a la vida. Y estas casas son, entre todas las obras de arquitectura, las que mejor retienen este carácter del habitar. Lo cotidiano es variable, efímero por naturaleza, como lo es el interior de estas casas: objetos, muebles, plantas... todo aquello vinculado al uso del habitante, se transforma, cambia de posición, aparece y desaparece con el paso del tiempo. Esos espacios domésticos conforman una historia de la arquitectura en sí mismos, fiel reflejo de una cultura universal, la del hombre contemporáneo en su vivir en la casa (Postiglione, 2004).

En la construcción también se mezclan la innovación con el uso de sistemas tradicionales. Can Lis supone una nueva lectura de un material local, el marès, que retoma, años más tarde, Carlos Ferrater en su pabellón de invitados en Menorca (1998). Breuer experimenta con el balloon frame en sus casas americanas, llevándolo al límite en New Canaan I (1948) ${ }^{12}$. También con ingenio constructivo y aspiraciones vanguardistas, pero recurriendo a sistemas tradicionales y elementos de pequeño tamaño, se construye la casa de Melnikov: una retícula de ladrillo da forma a los cilindros, perforados como una cesta y cubiertos por un forjado reticular de vigas de madera, que se construye en un entorno familiar. Artesanales también los sistemas de construcción en hormigón en la casa de Schindler o Lassen. Todos ellos realizados con pocos medios y medidas ajustadas, sujetas al módulo, que llevan al límite las capacidades plásticas y constructivas del material, y en los que el arquitecto gusta de ver la mano del hombre: "yo mismo la levanté... un pequeño Panteón" (Balslev, 1989, 73) ${ }^{13}$.

Figura 9. Casa Melnikov, Moscú (Rusia)

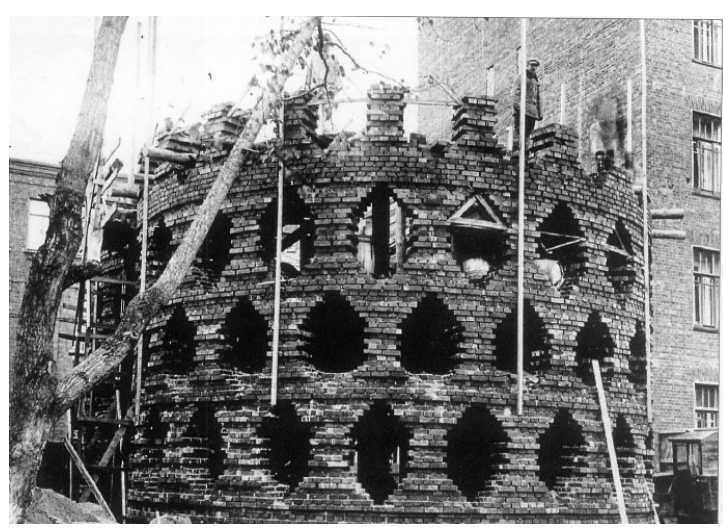

Fuente: Desconocida.

Tradición y modernidad se suman en las reformas de Coderch y Milà (1958), Bombelli (1961) o Federico Correa (1962) en Cadaqués, de Broner en Ibiza o Sáenz de Oiza en Mallorca (1965-1985). En estas actuaciones en la costa mediterránea, la introducción de nuevos modos de habitar, se hace con el rigor geométrico y el lenguaje plástico de la modernidad, de una forma elegante y austera (Terradas, 1993). Al trabajar desde el respeto al lugar y a su historia, las obras se incorporan a esa cultura milenaria. El arquitecto no impone, sino que recoge, transforma y aporta nuevos modos, añade un nuevo eslabón en la cadena de la historia, "como lo fue, en su tiempo, la Catedral de Florencia" (Alday, 1996, 59) ${ }^{14}$.

Cuando el arquitecto construye su vivienda, añade al riesgo económico, personal y familiar, el profesional, porque al adoptar nuevos modos de habitar y de construir, se sitúa siempre más allá de lo establecido, de lo usual y conocido, y porque la experimentación extrema, en el habitar y en el construir, pone a prueba la vida en la

\footnotetext{
${ }^{12}$ El arquitecto se muda, a los pocos años, a otra casa cercana, New Canaan II, de planta baja, muros de piedra y patios.

13 Son palabras de Mogens Lassen.

${ }^{14}$ Palabras de Melnikov, citadas en Iñaki Alday, Aprendiendo de todas sus casas.
} 
casa. Pero el arquitecto sabe que finalmente es la casa la que más ofrece, devolviendo con creces el sacrificio realizado.

\subsection{Hombre y arquitecto}

Finalmente, las vidas de estos arquitectos, como las de los artistas de Vasari, se muestran siempre vinculadas a la profesión, al oficio (Vasari, 2002). Vida y trabajo van tan ligados que la casa aparece muchas veces como resultado de un encargo, de una inversión, o a cuenta de unos honorarios. Entre éstos últimos, los ejemplos de Rietveld en el cine de Utrecht, Aalto en Munkkiniemi (1936), Neutra en la VDL. Otras veces, promociones que se planteaban para vender, acaban siendo ocupadas por ellos mismos y sus amigos: Lassen y el ingeniero Ishoy en Solystvej, Korsmo y Norberg Schultz en Planetveien.

Figura 10. Casa Lassen, Copenhague (Dinamarca)

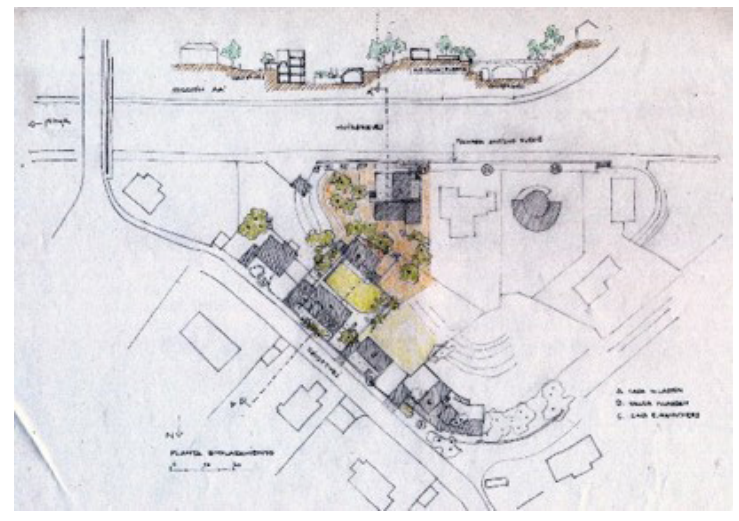

Fuente: Dibujo de la autora.

Cuando el arquitecto se asienta en un nuevo lugar lo hace muchas veces por una amistad, un vínculo humano. Coderch introduce a Harnden en Cadaqués (Arnal, 2012) ${ }^{15}$, B.Rudofsky llega a Málaga de la mano de José Guerrero, quien ya tenía una casa en la vecina Nerja, obra de Fernández del Amo, y lo hace con un proyecto firmado por Coderch. Finalmente, es conocida la amistad de Le Corbusier con la familia Rebutato, que lo acoge durante años en l'Étoile de Mer, donde construirá Le Cabanon y residirá en sus vacaciones y tiem- pos de descanso, hasta su muerte en las rocas en 1965 (Autora, 2015).

Figura 11. L'étoile de mer, Cap Martin (Francia)

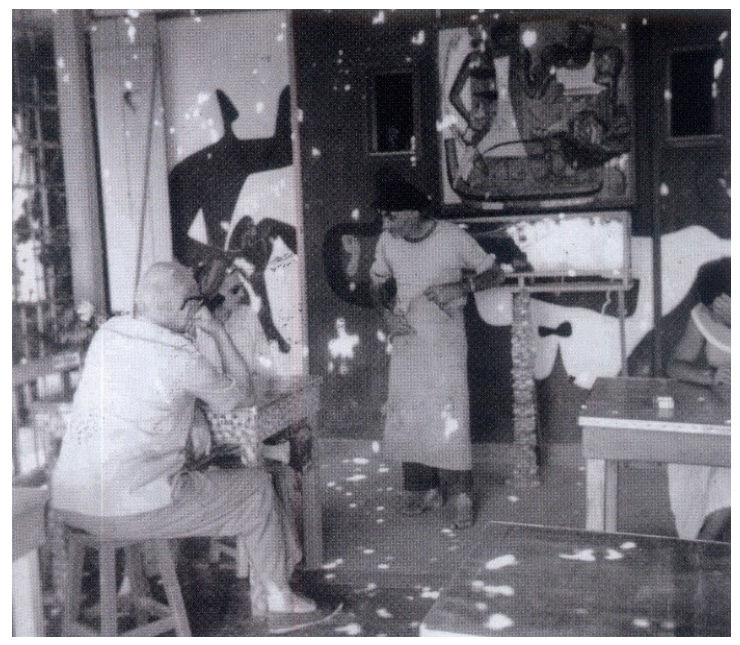

Fuente: Fondation Le Corbusier.

La relación con la obra propia se da por principio y el arquitecto utiliza el proyecto de su casa para probar aquello con lo que está trabajando. Gordon Bunshaft aplica el sistema de vigas de hormigón pi a su casa en los Hamptons, la Travertine House (1963), ya desaparecida. Egon Eiermann construye su casa-taller de Baden-Baden (1962), como un ejercicio más de fachada con elementos ligeros. Dos grandes obras, que quizás confirman, más que aventuran. En el otro extremo, El Laberinto de André Bloc en Mojácar (1972), un experimento más del autor, de escultura a tamaño real, nunca habitado, que ahora se muestra como icono de la población. También los sistemas de prefabricación se experimentan en el propio jardín: la Expansiva de Utzon (1969), o la casa de veraneo de Kristian Gullichsen, el mejor ejemplo construido de Moduli (1969).

Pero es éste un camino de ida y vuelta, porque el habitar en la casa aporta al arquitecto comprobaciones y aprendizajes, que aplicará en obras posteriores. Es ésta una característica específica de la casa propia, y su mayor beneficio, la única ocasión de extender su experiencia a los demás.

Porque por su vocación de servicio, la vivienda propia se presenta a menudo como manifiesto o como prototipo, "una expresión honesta y fiel

\footnotetext{
${ }^{15}$ En esa población se darán cita en los siguientes años personajes de gran nivel cultural: Staempfli, Duchamp, Callery, Hamilton, Tharrats, Corberó, etc. Ver tesis doctoral de Marc Arnal.
} 
de su trabajo, que ofrece a los demás lo que desea para sí" (Lleó, 1998, 127). Le Cabanon es la célula mínima del habitar; la casa cilíndrica de Melnikov forma bloques de viviendas; la de Cambridge de Sert (1958) se repite en hilera. De una forma más poética, Figini propone su casa de Milán como vivienda apilable, porque "un prisma de aire y de cielo no debería faltarle a nadie" (Savi, $1990,133)^{16}$. Pero ninguna de ellas llegó a repetirse, y se mantienen en la historia como ejemplos únicos, sólo para sus dueños, casi como un caparazón que acoge y protege la vida del autor.

Con la construcción de su casa, el arquitecto busca el encontrarse consigo mismo. Vocaciones $\mathrm{y}$ anhelos, pero sobre todo recuerdos, nostalgias y trozos de la vida, se introducen en estos proyectos. Es este mirar hacia el interior, hacia lo más íntimo, lo que hace especiales estas casas. La casa del Barrio de los Periodistas de Figini tiene su motivo de ser en las vivencias infantiles del arquitecto italiano: juegos y baños, flores y frutos en la terraza de la casa materna, y el dormitorio compartido de la familia Melnikov, en la cabaña a las afueras de Moscú, en la que el arquitecto había crecido de niño. O el tapanco de Barragán, otro rasgo de lo popular en la obra del arquitecto mejicano: "el lugar de la intimidad, el lugar secreto, un niño nunca puede imaginarse siquiera lo que hay en un tapanco..., allí sueño y duermo en la noche" (Riggen, 2001, 111) ${ }^{17}$.

Algunas veces esa introspección profunda tiene consecuencias imprevistas para la vida y la obra del arquitecto. En el caso de Lassen, un largo y obstinado proceso por asentar la casa en el lugar, por encontrar un lugar ideal en el que trabajar, tiene en la habitación de los conos de hormigón su episodio más sorprendente. Ésta, pensada como taller de arquitectura, se convierte en un espacio mágico, secreto, que permanece vacío y sin acondicionar, donde esconderse con los amigos cuando le sorprendía la lluvia.

Porque como cualquiera que construye su vivienda, el arquitecto busca poder hacer en ella lo que le apetece, sentirse libre. Aunque muchas veces esta característica, la de vivir, trabajar, y pensar en libertad, les haga ya distinguirse, a ellos y a sus casas, de la mayoría, "de la gran masa indisci- plinada donde los individuos viven sin tensión ni rigor, cómodamente apoyados los unos en otros y todos a la deriva, vil botín de las resacas" (Ortega y Gasset, 1964, 31).

La casa propia es pues, territorio de libertad, y de ello dan fe fotografías entrañables de estos maestros en su entorno cotidiano: la de Schindler con Moser en el patio, la de un joven Figini practicando escalada en la terraza a doble altura, o la del matrimonio Korsmo bailando en la habitación, muebles plegados. Finalmente, las de un Lassen mayor, fumando en el jardín, o un Melnikov anciano, mirada serena, frente al cristal de la fachada principal, "espléndido escaparate doméstico", en su casa de Moscú "una obra animada por un sueño" (Alday, 1996, 58) 18. $^{18}$

Figura 12. Casa Schindler, Hollywood (California)

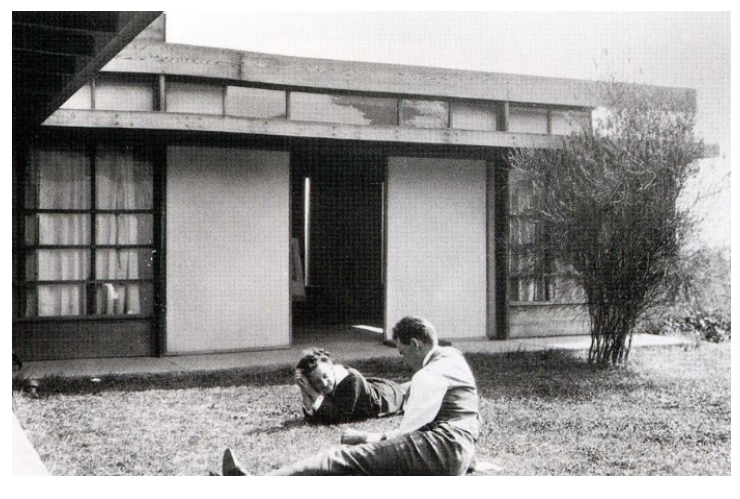

Fuente: Werner Moser Archive, ETH Zurich

\section{Referencias bibliográficas.}

Alday, I. (1996). Aprendiendo de todas sus casas (catálogo exposición con escritos de Josep Llinàs, José Antonio Martínez Lapeña i Rafael Moneo). Barcelona: UPC.

Arnal, M. (2016). L'art de viure. Cases per a artistes a Cadaqués. L'art concret com a generador d'arquitectura. Peter Harnden i Lanfranco Bombelli, (tesis doctoral inédita), Barcelona: Universitat Ramon Llull. http://www.tesisenred. net/handle/10803/392131

Bachelard, G. (1965). La poética del espacio, Buenos Aires: Fondo de Cultura Económica.

\footnotetext{
${ }^{16}$ Luigi Figini, “Appunti per una casa”. Traducción de la autora.

17 Entrevista a Luis Barragán, por Elena Poniatowska.

18 En el escrito de José Llinás, Un estupendo fracaso.
} 
Balslev Jorgensen, L. (1989). Mogens Lassen. Arkitekten, Copenhague: Arkitektens Forlag. Cid, Daniel, Sala, Teresa-M (2012). Las casas de la vida. Barcelona: Ariel.

De la Sota, A. (1989). Alejandro de la Sota. Arquitecto, Madrid: Pronaos.

Fernández Galiano, L. (2007). "Esparta y Síbaris: Bernard Rudofsky, disciplina y hedonismo", $A r$ quitectura Viva, ${ }^{\circ} 114$.

Figueroa Castejón, A. (1989). El arte de ver con inocencia. Pláticas con Luis Barragán, México: Universidad Autónoma Metropolitana.

Lleó, B. (1998). Sueño de habitar, Barcelona: Caja de Arquitectos.

Autora (2008). La casa del arquitecto (tesis doctoral inédita). Barcelona: Departamento Proyectos Arquitectónicos, Universitat Politècnica Catalunya. Autora (2011). "Una investigación sobre cómo investigar lo que el arquitecto investiga cuando construye su propia casa", Actas de Congreso $4^{\mathrm{a}}$ Jornadas Internacionales sobre Investigación en Arquitectura y Urbanismo, 4IAU, Valencia.

Autora (2015). Le Corbusier en Cap Martin, hombre-arquitecto, Actas del Congreso Le Corbusier 50 Years, Valencia.

Moller, Henrik Sten, Udsen, Vibe (2004). Jörn Utzon. Houses, Copenhague: Living Architecture.

Neumeyer, F. (1995). Mies van der Rohe, La palabra sin artificio. Reflexiones sobre la arquitectura 1922-1968, Madrid: El Croquis.

Neutra, R. (1951). Mystery and Realities of the Site, New York: Morgan \& Morgan.

Ortega y Gasset, J. (1987). El tema de nuestro tiempo, Madrid: Espasa Calpe.

Ortega y Gasset, J. (1964). Meditación del pueblo joven, Madrid: Espasa Calpe.

Outeiro, E., ed. (2011). Cabañas para pensar. Madrid : Maia.

Petit, J. (1970), Le Corbusier lui-même, Ginebra: Rousseau.

Postiglione, G., ed. (2004). One hundred houses for one hundred European architects of the twentieth century. Colonia: Taschen. http://www. meamnet.polimi.it

Riggen, A. (2011). Luis Barragán. Escritos y conversaciones, Madrid: El Croquis.

Savi, V. (1990). Figini e Pollini. Architetture 1927-1989, Milán: Electa.

Schindler, R. M. (1984), "La Casa Contemporánea", en R.M.Schindler. Arquitecto, Madrid: MOPU.

Sharr, A. (2008), La cabaña de Heidegger. Un espacio para pensar, Barcelona: Gustavo Gili.
Tanizaki, J. (1994), El elogio de la sombra, Madrid: Siruela.

Terradas, E. (1993), Cadaqués: Laboratorio del Realismo doméstico en Cataluña, tesis doctoral inédita, Barcelona: Departament de Projectes Arquitectònics, Universitat Politècnica Catalunya. http://www.tesisenred.net/handle/10803/5878.

Trigueiros, L., ed. (1993), Fernando Távora, Lisboa: Blau.

Vasari, G. (2002), Las vidas de los más excelentes arquitectos, pintores y escultores italianos, desde Cimabue hasta nuestros tiempos. Madrid: Cátedra. 